\title{
Enhanced Climate Control of Semi-arid and Arid Greenhouses Equipped with Fogging Systems
}

BARD Project Number: US-4122-08

$\underline{\text { Investigators }}$

Principal Investigator (PI):

Raphael Linker

Co-Principal Investigator (Co-PI):

Murat Kacira

Collaborating Investigators:

Avraham Arbel

Chieri Kubota

Gene Giacomelli $\underline{\text { Institutions }}$

Technion

University of Arizona

Agricultural Research Organization

University of Arizona

University of Arizona 


\section{Final Scientific Report \\ Cover Page}

BARD Project Number: US-4122-08

Date of Submission of the report: March 26, 2012

Project Title: Enhanced Climate Control of Semi-arid and Arid Greenhouses Equipped with Fogging Systems

Investigators

Principal Investigator (PI):

Raphael Linker

Co-Principal Investigator (Co-PI):

Murat Kacira

Collaborating Investigators:

Avraham Arbel

Chieri Kubota

Gene Giacomelli

\section{$\underline{\text { Institutions }}$}

Technion

University of Arizona

Agricultural Research Organization

University of Arizona

University of Arizona

Keywords Controlled environment agriculture; Ventilation; Cooling; Modeling; Resource savings; Climate control strategy.

Abbreviations commonly used in the report, in alphabetical order:

ARO

CFR

ET

QFT

VVFR

VPD

Budget: IS: $\$ 145,000$ agriculture research organization

constant fogging rate

evapotranspiration

quantitative feedback theory

variable vent and fogging rate

vapor pressure deficit
Signature

Principal Investigator
US: $\$ 160,000 \quad$ Total: $\$ 305,000$ 


\section{Final Scientific Report}

Publication Summary (numbers)

\begin{tabular}{|l|c|c|c|c|}
\hline & $\begin{array}{c}\text { Joint } \\
\text { IS/US } \\
\text { authorship }\end{array}$ & $\begin{array}{c}\text { US Authors } \\
\text { only }\end{array}$ & $\begin{array}{c}\text { Israeli } \\
\text { Authors } \\
\text { only }\end{array}$ & Total \\
\hline $\begin{array}{l}\text { Refereed (published, in press, accepted) } \\
\text { BARD support acknowledged }\end{array}$ & 3 & - & - & 3 \\
\hline Submitted, in review, in preparation & 2 & - & - & 2 \\
\hline Invited review papers & - & - & - & - \\
\hline Book chapters & - & - & - & - \\
\hline Books & - & - & $2^{+}$ & 3 \\
\hline Master theses & - & 1 & - & 1 \\
\hline Ph.D. theses & - & 1 & - & 1 \\
\hline Abstracts & 3 & 1 & 2 & 6 \\
\hline Not refereed (proceedings, reports, etc.) & - & - & - \\
\hline
\end{tabular}

${ }^{+}$this includes a MSc student from Wageningen University (The Netherlands) who spent one semester at the Technion to write the first half of his thesis on "Modeling and controller design for fogging in a naturally ventilated greenhouse"

*this includes a MSc student in University of Arizona who is using some of the greenhouse climatic variables measured for validation of a computational fluid dynamics simulation model to analyze greenhouse aerodynamics.

\section{Postdoctoral Training:}

- Dr. Efren Fitz-Rodriguez, post doctoral researcher (supervised by Dr. Murat Kacira)

\section{Cooperation Summary (numbers)}

\begin{tabular}{|l|c|c|c|c|}
\hline & $\begin{array}{c}\text { From US to } \\
\text { Israel }\end{array}$ & $\begin{array}{c}\text { From Israel } \\
\text { to US }\end{array}$ & $\begin{array}{c}\text { Together, } \\
\text { elsewhere }\end{array}$ & Total \\
\hline $\begin{array}{l}\text { Short Visits \& } \\
\text { Meetings }\end{array}$ & 1 & 1 & 0 & 2 \\
\hline $\begin{array}{l}\text { Longer Visits } \\
\text { (Sabbaticals) }\end{array}$ & 0 & 0 & 0 & 0 \\
\hline $\begin{array}{l}\text { Project Progress } \\
\text { Meeting at ASABE } \\
\text { Annual Meeting }\end{array}$ & 0 & 0 & 1 & 1 \\
\hline
\end{tabular}

\section{Description of Cooperation:}

Two site visits were accomplished, one to Israel (July 2010) and one to the US (Feb 2011). Joint work was accomplished at each site during the visits. This collaboration resulted in conference presentations and proceedings papers as well as publications of peer-reviewed manuscripts in journals. We have promoted the project, its findings and also information on BARD during the conference presentations and at various meetings.

Patent Summary (numbers)

\begin{tabular}{|l|c|c|c|c|}
\hline & $\begin{array}{c}\text { Israeli } \\
\text { inventor } \\
\text { only }\end{array}$ & $\begin{array}{c}\text { US inventor } \\
\text { only }\end{array}$ & $\begin{array}{c}\text { Joint } \\
\text { IS/US } \\
\text { inventors }\end{array}$ & Total \\
\hline Submitted & 0 & 0 & 0 & 0 \\
\hline $\begin{array}{l}\text { Issued } \\
\text { (allowed) }\end{array}$ & 0 & 0 & 0 & 0 \\
\hline Licensed & 0 & 0 & 0 & 0 \\
\hline
\end{tabular}




\title{
Final Scientific Report
}

\begin{abstract}
The main objectives were (1) to develop, implement and validate control procedures that would make it possible to maintain year-round air temperature and humidity at levels suitable for crop cultivation in greenhouses operating in arid and semi-arid regions and (2) to investigate the influence of the operational flexibility of the fogging system on the performance of the system. With respect to the development of climate controllers, we developed a new control approach according to which ventilation is used to maintain the enthalpy of the greenhouse air and fogging is used to adjust the humidity ratio inside the greenhouse. This approach is suitable mostly for greenhouses equipped with mechanized ventilation, and in which the air exchange rate can be controlled with enough confidence. The development and initial validation of the controllers were performed in a small experimental greenhouses located at the Agricultural Research Organization and very good tracking were obtained for both air temperature and relative humidity (maximum mean deviations over a 10-min period with constant setpoints lower than $2.5^{\circ} \mathrm{C}$ and $5 \%$ relative humidity). The robust design approach used to develop the controllers made it possible to transfer successfully these controllers to a much larger semi-commercial greenhouse located in the much drier Arava region. After only minimal adjustments, which did not require lengthy dedicated experiments, satisfactory tracking of the temperature and humidity was achieved, with standard deviation of the tracking error lower than $1^{\circ} \mathrm{C}$ and $5 \%$ for temperature and relative humidity, respectively. These results should help promote the acceptance of modern techniques for designing greenhouse climate controllers, especially since given the large variety of greenhouse structures (shape, size, crop system), developing high performance site-specific controllers for each greenhouse is not feasible. In parallel to this work, a new cooling control strategy, which considers the contribution of humidification and cooling from the crop, was developed for greenhouses equipped with natural ventilation. Prior to the development of the cooling strategy itself, three evapotranspiration models were compared in terms of accuracy and reliability. The cooling strategy that has been developed controls the amount of fog introduced into the greenhouse as well as the percentage of vent openings based on the desired vapor pressure deficit (VPD) and enthalpy, respectively. Numerical simulations were used to compare the performance of the new strategy with a constant fogging rate strategy based on VPD, and on average, the new strategy saved 36\% water and consumed 30\% less electric energy. In addition, smaller air temperature and relative humidity fluctuations were achieved when using the new strategy. Finally, it was demonstrated that dynamically varying the fog rate and properly selecting the number of nozzles, yields additional water and electricity savings.
\end{abstract}




\section{Final Scientific Report}

\section{Achievements}

\section{Greenhouses equipped with forced ventilation}

We have demonstrated the soundness of the control approach outlined in the original proposal, namely using the ventilation rate to adjust the air enthalpy and the fogging rate to adjust the greenhouse humidity (Figure 1). In terms of control, this approach led to partial decoupling of the controlled variables and the corresponding design of two single-input-single-output (SISO) controllers rather than a multiple-inputsmultiple-outputs (MIMO) controller. This approach led to tracking errors of less than $2.5^{\circ} \mathrm{C}$ and $5 \%$ for temperature and relative humidity, respectively. The robust feedback controllers were designed according to the Quantitative Feedback Theory (QFT) methodology, taking into account large uncertainties in the parameters of the greenhouse model as well as in the fluxes delivered by the fans and fog nozzles. As a result, it was possible to transfer controllers originally designed in a small experimental greenhouse located at the ARO to a much larger greenhouse located in the Arava region. The only steps required prior to the implementation of the controllers were to verify that the new greenhouse fell within the uncertainty range considered at the design stage and to obtain inverse models of the actuators, which required only simple measurements that could be conducted within a few hours. The information obtained led to updating the inverse models of the actuators (shaded components in Figure 1) but did not affect the feedback controllers themselves. In other words, we demonstrated the possibility to design a generic climate controller that can be easily fine-tuned to a particular greenhouse. This result should help promote the acceptance of modern techniques for designing greenhouse climate controllers, especially since given the large variety of greenhouse structures (shape, size, crop system), developing high performance site-specific controllers for each greenhouse is not feasible. 


\section{Final Scientific Report}

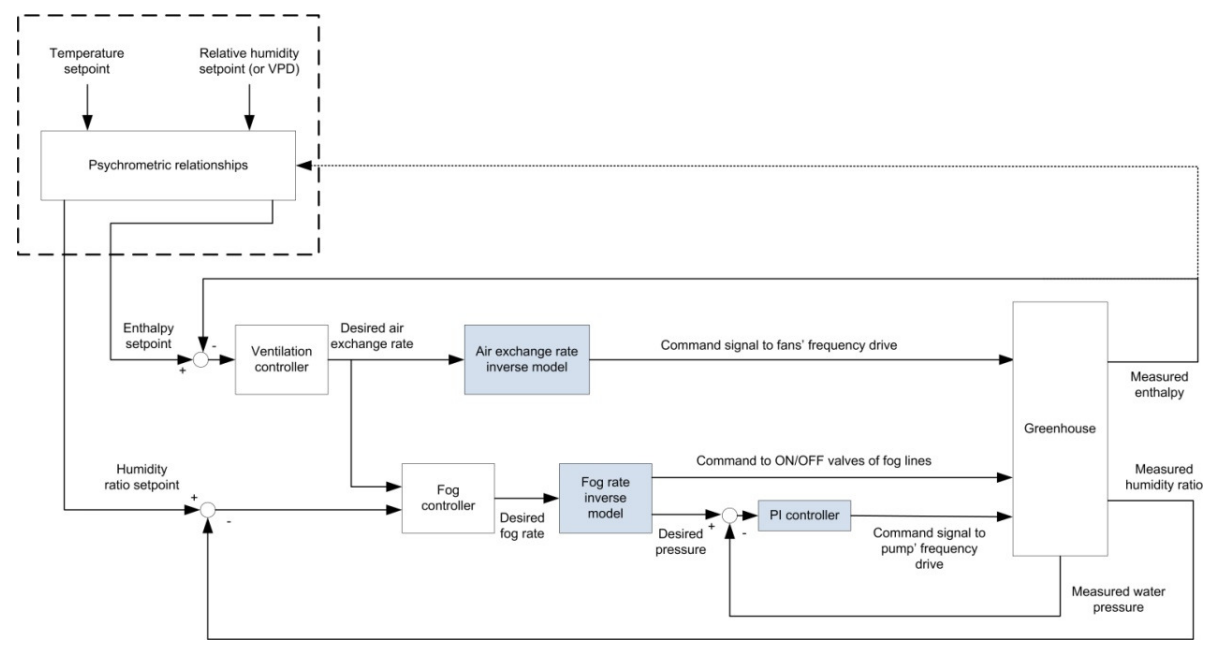

Fig. 1: Control scheme based on partial decoupling between the two feedback loops. The shaded blocks indicate components that need to be updated for each greenhouse. Naturally ventilated greenhouses

We evaluated three theoretical models (Stanghellini, Penman-Monteith and Takakura) to simulate the evapotranspiration (ET) with tomato crop under natural ventilation with fog cooling and for three growing seasons. ET from the models were compared to measured values obtained from sap flow gauges. Even though Stanghellini model produced the smallest deviations of the predicted ET from the measured ET, having the best overall performance under all conditions evaluated, an analysis of variance of the daily mean square errors did not show significant differences $(\alpha=0.05)$ between the three models, suggesting that any of the three models could be used for inclusion in a greenhouse cooling climate control strategy. The need for parameters such as stomatal and aerodynamic resistances or leaf area index restricts the use of the models of PenmanMonteith and Stanghellini in practice. The Takakura model was found to be easier to implement although as the crop grows, careful adjustments on the height of the solarimeter used for this approach are required.

A new cooling control strategy, variable vent and fogging rate (VVFR), which considered the contribution of humidification and cooling from the crop, was evaluated by computer simulations (Figure 2). The strategy controlled the amount of fog introduced into the greenhouse, as well as the percentage of vent openings to maintain desired values of greenhouse atmospheric vapor pressure deficit (VPD) and enthalpy, respectively. The performance was compared to constant fogging rate (CFR) strategy, which was based on a VPD setpoint of $1.0 \mathrm{kPa}$ with a \pm 0.2 bandwidth. 


\section{Final Scientific Report}

The simulations started with closed vents that changed to a fully open position when greenhouse air temperature reached $25^{\circ} \mathrm{C}$. Under the VVFR control strategy, a control for the vent configurations based on enthalpies was developed with a specific enthalpy setpoint of $56 \mathrm{~kJ} \mathrm{~kg}^{-1}$ (Humid air at $24^{\circ} \mathrm{C}$ and VPD of $1.0 \mathrm{kPa}$ falls on this same isenthalpic line). Percent vent opening configurations of 0-0, 0-25, 25-25, 25-50, $50-50,50-75,75-75,75-100$, and 100-100 of the side/roof vents, were pre-established.

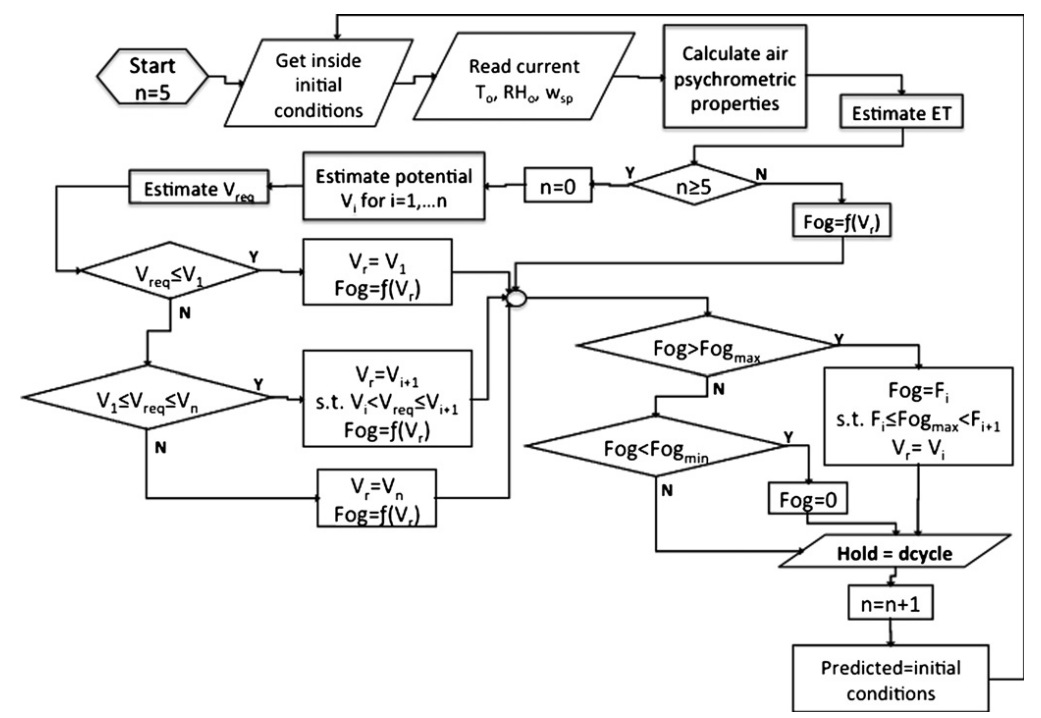

Fig. 2: Control logic for the variable fogging rates strategy. $n$ is a counter, $i=[1, \ldots, n], i$

is the number of vent configurations tested. (Villarreal Guerrero et al., 2012b)

The results showed that lower average air temperature and VPD values closer to the selected setpoints were achieved while using less electric energy and water when the system was operated according to the VVFR strategy. Both the water and electric energy use were lower under the VVFR strategy due to the ability of the system to control both the fog rates and the vent configurations. Pump cycling was reduced with the VVFR strategy only during the summer day evaluated and for the highest fog rate ranges studied. For the rest of the scenarios investigated, the CFR produced fewer onoff switching due to the fact that the system was not able to meet the fog demands for cooling and the pump stayed on most of the day. This study showed that the system flexibility was improved with dynamic vent opening control and variable rate highpressure fog as it was possible to maintain greenhouse conditions closer to the desired levels with improved temporal uniformity of the environmental variables and with water and electrical energy savings. On average, the new strategy saved $36 \%$ water and consumed $30 \%$ less electric energy. 


\section{Final Scientific Report}

\section{Details of cooperation}

We have established strong collaboration and interaction between the researchers and students involved in the projects. Two site visits were accomplished, one to Israel and one to the US. During these visits, we had project progress discussions, worked in the research labs, visited project greenhouses, and also visited research centers and commercial greenhouse operations. This collaboration resulted in conference presentations/papers as well as in peer-reviewed scientific publications. We have promoted the project, its findings and also general information on BARD programs during the conference presentations and at various meetings. We also had the opportunity to present brief information about our BARD project, its objectives, and details on our collaborative activities during a meeting at the University of Arizona organized by Arid Lands Sustainable BioEnergy Institute, College of Agriculture and Life Sciences, with invited guests Dr. Edo Chalutz, Executive Director of the BARD Foundation, and Mr. Zvi Herman, representative of the Ministry of Agriculture and Science (Canada, Mexico, and USA) from the Embassy of Israel in Washington D.C, as well as other colleagues at the University of Arizona.

We are looking forward to collaborate further and apply for future funding related to the research conducted in this project as well as to other research topics of mutual interest.

\section{List of reviewed publications}

\section{$\underline{\text { Published }}$}

1. Linker, R., M. Kacira and A. Arbel (2011). Robust climate control of a greenhouse equipped with variable-speed fans and a variable-pressure fogging system. Biosystems Engineering, 110: 153-167.

2. Villarreal Guerrero, F., M. Kacira, E. Fitz-Rodriguez, C. Kubota, G. A. Giacomelli., R. Linker and A. Arbel (2012a). Comparison of three evapotranspiration models for a cooling strategy within a naturally ventilated greenhouse equipped with variable rate fogging system. Scientia Horticulturae, 134:210-221. 


\section{Final Scientific Report}

3. Villarreal Guerrero, F., M. Kacira, E. Fitz-Rodriguez, R. Linker, C. Kubota, G. A. Giacomelli and A. Arbel (2012b). Simulated performance of a greenhouse cooling control strategy with natural ventilation and variable fogging rates. Biosystems Engineeering, 111: 217-228.

$\underline{\text { Submitted }}$

1. Linker, R., A. Arbel, M. Kacira, and O. Gutman. Robustness and transferability of fogging and ventilation controllers for mechanically ventilated greenhouses. Submitted to Computers and Electronics in Agriculture. (In review)

\section{$\underline{\text { In preparation }}$}

1. Villarreal-Guerrero, F., M. Kacira, E. Fitz-Rodríguez, R. Linker, G.A. Giacomelli, A. Arbel, C. Kubota. Implementation of a greenhouse cooling strategy with natural ventilation and variable fogging rates. (To be submitted to Transactions of the ASABE) 


\section{Final Scientific Report}

\section{Appendix}

\section{Content}

Linker, R., M. Kacira and A. Arbel (2011). Robust climate control of a greenhouse equipped with variable-speed fans and a variable-pressure fogging system. Biosystems Engineering, 110: 153-167.

Villarreal Guerrero, F., M. Kacira, E. Fitz-Rodriguez, C. Kubota, G. A. Giacomelli., R. Linker and A. Arbel (2012). Comparison of three evapotranspiration models for a cooling strategy within a naturally ventilated greenhouse equipped with variable rate fogging system. Scientia Horticulturae, 134:210-221.

Villarreal Guerrero, F., M. Kacira, E. Fitz-Rodriguez, R. Linker, C. Kubota, G. A. Giacomelli and A. Arbel (2012). Simulated performance of a greenhouse cooling control strategy with natural ventilation and variable fogging rates. Biosystems Engineeering, 111: 217-228.

Villarreal-Guerrero, F., M. Kacira, and E. Fitz- Rodriguez, G. Giacomelli, C. Kubota, R. Linker, A. Arbel. Simulation of fixed and variable pressure fogging in naturally ventilated greenhouse, water and energy savings and stability of climate. ActaHorticulturae. (In Press)

Fitz-Rodriguez, E., M. Kacira, F. Villarreal-Guerrero, G. Giacomelli, C. Kubota, R. Linker, A. Arbel. Neural network predictive control in a naturally ventilated and fog cooled greenhouse. ActaHorticulturae. (In Press)

Linker, R., A. Arbel, M. Kacira, and O. Gutman. Robustness and transferability of fogging and ventilation controllers for mechanically ventilated greenhouses. Submitted to Computers and Electronics in Agriculture.

Summary of: Villarreal Guerrero, F., M. Kacira, E. Fitz-Rodriguez, R. Linker, C. Kubota, G. A. Giacomelli and A. Arbel. Implementation of a greenhouse cooling strategy with natural ventilation and variable fogging rates. (Will be submitted to Transactions of the ASABE)

Robust feedback control of fogging rate in naturally-ventilated greenhouse (unpublished results) 